EMPOWER: Jurnal Pengembangan Masyarakat Islam

Vol. 5, No. 2, Desember 2020, hlm. 21-39

e-ISSN: 2580-0973, p-ISSN: 2580-085X

Tersedia online di: http://syekhnurjati.ac.id/jurnal/index.php/empower

Email: empowerjurnal@gmail.com

\title{
Program Pemberdayaan Masyarakat Kelompok Ternak Ngudi Mulyo Panggang oleh PT. Pertamina (Persero) Fuel Terminal Rewulu
}

\author{
Muhammad Nasib* \\ (Program Studi Pengembangan Masyarakat Islam, Fakultas Dakwah dan \\ Komunikasi, UIN Sunan Kalijaga, Yogyakarta) \\ E-mail: muhamadnasib6@gmail.com \\ Shindy Karenina** \\ (Program Studi Pengembangan Masyarakat Islam, Fakultas Dakwah dan \\ Komunikasi, \\ UIN Sunan Kalijaga, Yogyakarta) \\ E-mail: kareninashindy@gmail.com
}
Alif Laela***
(Program Studi Pengembangan Masyarakat Islam, Fakultas Dakwah dan Komunikasi, UIN Sunan Kalijaga, Yogyakarta)
E-mail: aliflaela6@gmail.com

\section{Rifky Amri Amrullah****}

(Program Studi Pengembangan Masyarakat Islam, Fakultas Dakwah dan

Komunikasi,

UIN Sunan Kalijaga, Yogyakarta)

E-mail: rifkyamriamrullah@gmail.com

\section{Mohammad Safri Fauzi*****}

(Program Studi Pengembangan Masyarakat Islam, Fakultas Dakwah dan

Komunikasi,

UIN Sunan Kalijaga, Yogyakarta)

E-mail: muhamadnasib6@gmail.com 


\title{
Muhammad Iqbal ${ }^{* * * * * *}$
}

(Program Studi Pengembangan Masyarakat Islam, Fakultas Dakwah dan Komunikasi, UIN Sunan Kalijaga, Yogyakarta)

E-mail: ibalsuper11@gmail.com

\section{Article History}

Submitted: 29.04.2020, Revised: 05.10.2020, Accepted: 09.12.2020

\begin{abstract}
Corporate Social Responsibility is an obligation carried out by a company as regulated in article 74 paragraph (1) of Law Number 40 of 2007 concerning Limited Liability Companies. Therefore, it is necessary to implement real to the community by providing empowerment programs that are in accordance with the needs. So that the assistance of corporate social responsibility is very necessary. This research uses qualitative approach, namely the study of community empowerment program. The purpose of this research is to find out the implementation of community empowerment programs implemented by CSR PT. Pertamina (Persero) Fuel Terminal Rewulu. The results showed that the implementation of CSR programs was responded well by members of the Ngudi Mulyo Panggang Livestock Group, but still lacked more in-depth assistance. The results of other research showed that livestock members are elderly people so that it becomes one of the factors that inhibit the performance and productivity of activities.
\end{abstract}

Keywords: implementation, empowerment program, corporate social responsibility

\begin{abstract}
Abstrak
Tanggung Jawab Sosial Perusahaan adalah kewajiban yang dilakukan oleh perusahaan yang diatur dalam pasal 74 ayat (1) Undang-Undang Nomor 40 Tahun 2007 tentang Perseroan Terbatas. Oleh karena itu perlu implementasi nyata kepada masyarakat dengan memberikan program pemberdayaan yang sesuai dengan kebutuhan. Sehingga pendampingan dari corporate social responsibility sangat diperlukan. Penelitian ini menggunakan pendekatan kualitatif yaitu studi program permberdayaan masyarakat. Tujuan penelitian ini untuk mengetahui implementasi program pemberdayaan masyarakat yang dilaksanakan CSR PT. Pertamina (Persero) Fuel Terminal
\end{abstract}


Rewulu. Hasil penelitian menunjukkan bahwa penerapan program CSR direspons dengan baik oleh anggota Kelompok Ternak Ngudi Mulyo Panggang, tetapi masih kurang pendampingan yang lebih mendalam. Hasil penelitian lain menujukkan anggota ternak ialah masyarakat yang sudah lanjut usia sehingga menjadi salah satu faktor yang menghambat kinerja dan produktivitas kegiatan.

Kata kunci: implementasi, program pemberdayaan, corporate social sesponsibility

\section{PENDAHULUAN}

Pemberdayaan adalah sebuah proses dan tujuan. Sebagai proses, pemberdayaan merupakan suatu kegiatan yang dapat memperkuat kekuasaan atau keberdayaan suatu kelompok yang lemah dalam masyarakat, termasuk individu-individu yang mengalami masalah kemiskinan. Sedangkan sebagai tujuan, maka pemberdayaan mengarah pada keadaan atau hasil yang ingin dicapai oleh sebuah perubahan sosial seperti masyarakat miskin yang berdaya, memiliki kekuasaan atau mempunyai pengetahuan dan kemampuan dalam memenuhi kebutuhan hidupnya baik dari segi fisik, ekonomi, maupun sosial seperti memiliki kepercayaan diri, mampu menyampaikan aspirasi, mempunyai mata pencaharian, berpartisipasi dalam kegiatan sosial, dan mandiri dalam melaksanakan tugas-tugas kehidupannya ${ }^{1}$.

Salah satu indikator berhasilnya pemberdayaan adalah masyarakat yang berdaya, selain itu wujud dari masyarakat berdaya adalah tercapainya kesejahteraan kehidupan masyarakat ${ }^{2}$. Masyarakat yang sejahtera tentunya dapat memanfaatkan potensi lingkungan (flora dan fauna) maupun masyatakat (skill) yang dimilikinya. Potensi lingkungan adalah hal yang biasanya paling menonjol dalam pemberdayaan masyarakat, selain itu perlu adanya kesadaran masyarakat dalam pengolahan. Setiap daerah

${ }^{1}$ Rauf A Hatu, "Pemberdayaan Dan Pendampingan Sosial Dalam Masyarakat (Suatu Kajian Teortis)," Inovasi 7, no. 4 (2010): 240-54.

${ }^{2}$ Safri Miradj and Sumarno Sumarno, "Pemberdayaan Masyarakat Miskin, Melalui Proses Pendidikan Nonformal, Upaya Meningkatkan Kesejahteraan Sosial Di Kabupaten Halmahera Barat," Jurnal Pendidikan Dan Pemberdayaan Masyarakat 1, no. 1 (2014): 101, https://doi.org/10.21831/jppm.v1i1.2360. 
memiliki potensi yang dapat diunggulkan sesuai dengan karakteristik wilayah, baik pedesaan maupun perkotaan.

Masyarakat di daerah pedesaan cenderung bekerja dalam sektor pertanian, guna kelangsungan hidup mereka ${ }^{3}$. Akan tetapi perlu juga mengembangkan sektor peternakan yang dapat memberikan dorongan dalam penyuburan tanaman masyarakat. Terdapat banyak potensi di Dusun Panggang yang bisa masyarakat kembangkan baik dari segi peternakan maupun segi pertanian. Potensi yang menonjol ialah segi peternakan. Peternakan merupakan suatu bagian dari kehidupan manusia yang juga memegang peranan penting dalam kebutuhan manusia. Jika dilihat lebih jauh, peternakan merupakan suatu usaha yang sangat menjanjikan kedepannya asalkan kita bisa konsisten menjaga usaha tersebut. Dari fakta yang ada, sangat banyak manusia yang mengkonsusmi daging hewan. Dengan banyaknya orang yang mengkonsumsi daging, susu, telur dan hasil ternak lainnya maka semakin besar juga peluang bagi peternak sendiri untuk menjadi sukses jangka panjang.

Peternakan dibagi menjadi 2 kelompok yaitu peternakan kecil dan peternakan besar. Peternakan kecil meliputi hewan kecil seperti ayam, kelinci, dan lain lain. Sedangkan peternakan besar meliputi hewan besar seperti sapi, kuda, kerbau, kambing dan lain sebagainya.

Dalam Undang-Undang masalah peternakan diatur dalam UU No. 18 Tahun 2009 tentang Peternakan dan Kesehatan hewan. Tujuan peternakan adalah untuk mencukupi kebutuhan masyarakat akan protein hewani, mewujudkan terbentuknya dan berkembangnya industri dan perdagangan bahan bahan yang berasal dari hewan hewan ternak, meningkatkan penghasilan dan taraf hidup rakyat terutama rakyat petani-peternak, serta mempertinggi daya guna tanah ${ }^{4}$.

Di peternakan perlu adanya manajemen pemeliharan ternak diperkenalkan sebagai upaya untuk dapat memberikan keuntungan yang

\footnotetext{
${ }^{3}$ Eka Nursiyamsih, "Kehidupan Sosial Ekonomi Petani Dalam Sistem Sewa Adol Oyodan Masyarakat Pedesaan" (Universitas Negeri Semarang, 2015).

${ }^{4}$ Hellyward Suyitman, Lily Warly, "Pengelolaan Peternakan Sapi Potong Ramah Lingkungan," Jurnal Hilirisasi IPTEKS 2, no. 3 (2019): 159-76.
} 
optimal bagi pemilik peternakan 5 . Dalam manajemen pemeliharaan ternak mempelajari seleksi bibit, pangan, kandang, sistem perkawinan, kesehatan hewan, tata laksana pemeliharaan dan pemasaran. Pakan yang berkualitas baik dan mengandung gizi cukup akan berpengaruh baik terhadap kesehatan dan mempercepat penggemukan, perkembang biakan, dan jumlah ternak yang mati juga akan berkurang.

Karena jika dikaji lebih dalam, dari jumlah keseluruhan anggota kelompok ternak ngudi mulyo yang beranggotakan 60 orang, sangat memungkinkan untuk mengolah limbah dari hewan ternak untuk dijadikan kompos. Selain itu, pupuk kompos yang diproduksi bisa diperjual belikan untuk menambah pendapatan anggota kelompok ternak. Untuk mewujudkan program pembangunan peternakan secara operasional diawali dengan pembentukan atau penataan kawasan melalui pendekatan sistem dan usaha agribisnis.

Dengan terbitnya Undang-Undang Nomor 40 Tahun 2007 tentang Perseroan Terbatas yang dalam salah satu pasalnya memuat kewajiban bagi perseroan yang menjalankan kegiatan usahanya di bidang dan/atau berkaitan dengan sumber daya alam, untuk melaksanakan Tanggung Jawab Sosial dan Lingkungan (TJSL), ditanggapi dengan beragam sikap oleh berbagai pihak. Corporate Social Responsibility (CSR) dapat didefinisikan sebagai tanggung jawab moral suatu perusahaan terhadap para stakeholders-nya, terutama komunitas atau masyarakat disekitar wilayah kerja dan pengoperasian perusahaan. Hal ini guna menciptakan sebuah keseimbangan dan pemerataan kesejahteraan sosial ekonomi masyarakat agar kecemburuan sosial tidak lagi berpotensi menjadi sumber konflik.

CSR dipandang sebagai suatu keharusan untuk menciptakan citra yang baik bagi suatu perusahaan. Praktik CSR yang berkelanjutan adalah sebuah investasi sosial yang berbuah pada kelancaran operasional perusahaan. Terlaksananya praktik-praktik yang bertanggung jawab terhadap lingkungan dan sosial akan meningkatkan nilai pemegang saham,

\footnotetext{
5 Suyitman, Lily Warly.
} 
dan berdampak pada peningkatan prestasi keuangan dan keberlanjutan perusahaan ${ }^{6}$.

Banyak cara untuk melakukan pemberdayaan, salah satu contohnya adalah CSR PT. Pertamina (Persero) Fuel Terminal Rewulu yang turut hadir guna meningkatkan nilai ekonomi masyarakat sekitarnya. CSR adalah sebuah program dimana perusahaan mengintegrasikan kepedulian sosial dalam operasi bisnis mereka. PT. Pertamina (Persero) Fuel Terminal Rewulu Yogyakarta sebagai perusahaan BUMN ikut berperan aktif melalui program CSR terhadap pemberdayaan masyarakat yang berada di sekitar kawasan perusahaan.

Salah satu desa binaan CSR PT. Pertamina (Persero) Terminal Rewulu adalah Kelompok Ternak Ngudi Mulyo yang terletak di Dusun Panggang tepatnya di Desa Argomulyo, Kecamatan Sedayu, Kabupaten Bantul. Kelompok Ternak Ngudi Mulyo sendiri merupakan kelompok kegiatan peternakan dari warga di dusun tersebut yang memelihara dan penggemukan ternak agar menghasilkan nilai ekonomi yang diharapkan dapat menambah pendapatan bagi anggotanya.

Kegiatan yang dilakukan di Kelompok Ternak Ngudi Mulyo antara lain yaitu pemanfaatan kotoran sapi untuk biogas serta pemanfaatan kotoran kambing untuk pembuatan pupuk kompos. Arti dari Ngudi Mulyo sendiri adalah 'ngudi' yang berarti mencari, sedangkan 'mulyo' memiliki arti sejahtera. Maksudnya yaitu diharapkan anggota dalam organisasi ini selalu merasa ingin berusaha untuk sejahtera, berbagi ilmu dan produktif dengan semangat kekeluargaan dan kebersamaan atau gotong royong.

CSR PT. Pertamina (Persero) Fuel Terminal Rewulu hadir untuk membantu meningkatkan ekonomi masyarakat sekitar dengan memaksimalkan hasil ternak yang dimiliki oleh warga Dusun Panggang. Harapan kedepannya adalah Kelompok Ternak Ngudi Mulyo memiliki sistem organisasi yang kuat serta memiliki penghasilan tambahan dari kelompook ternak tersebut.

\footnotetext{
${ }^{6}$ Nike Agustina, "Peran Corporate Social Responsibility (CSR) PT. Pertamina Hulu Energy WMO Dalam Pengembangan Masyarakat Di Kecamatan Gresik," Jurnal Akuntansi Unesa 1, no. 1 (2012).
} 
Dalam melakukan pemberdayaan, tentu banyak masalah yang dihadapi. Sebagai contoh ketidakmampuan masyarakat sekitar dalam mengelola potensi yang ada. Masyarakat Dusun Panggang belum dapat memahami potensi SDA yang mereka miliki, sehingga sampai saat ini hanya memandang peternakan sebagai mata pencarian sampingan.

Sudah banyak bentuk pelatihan yang diadakan guna meningkatkan skill dan pengetahuan masyarakat Dusun Panggang dalam mengelola peternakan. Namun sejauh ini pelatihan yang diberikan tidak memberikan efek apapun untuk kelompok ternak Ngudi Mulyo, hal ini disebabkan karena ilmu yang didapatkan ketika pelatihan tidak diterapkan dalam kegiatan beternak mereka.

Masalah lainnya yang timbul adalah usia anggota kelompok ternak yang terbilang sudah bukan usia produktif lagi. Pemuda sekitar yang seharusnya memiliki inovasi serta ide-ide terkini justru kurang tertarik untuk berhubungan dengan kelompok ternak, mereka justru membuat program sendiri yang tidak berkaitan dengan peternakan yaitu perikanan. Hal ini dikarenakan pola pikir masyarakat sekitar yang menganggap jika pemuda terlalu sibuk ikut terlibat dalam kegiatan desa akan kesulitan ketika mencari pekerjaan.

Berangkat dari latar belakang diatas, perlu pengkajian lebih lanjut mengenai tanggung jawab sosial perusahaan PT Pertamina (Persero) Fuel Terminal Rewulu sebagai perusahaan yang besar yang berada di lingkungan masyarakat sekitar. Peneliti akan merumuskan pertanyaan penelitian yaitu sebagai berikut: Bagaimana implementasi dan hasil program pemberdayaan masyarakat pada Kelompok Ternak Ngudi Mulyo Panggang oleh PT Pertamina (Persero Fuel Terminal Rewulu di Argomulyo Sedayu Bantul.

Lokasi penelitian dilakukan di Dusun Panggang, Desa Argomulyo, Kecamatan Sedayu, Kabupaten Bantul, Daerah Istimewah Yogyakarta, Yang berfokus pada Kelompok Ternak Ngudi Mulyo Panggang yang berada di ring satu PT Pertamina TBBM Rewulu. Penelitian ini menggunakan metode kualitatif, dengan teknik pengumpulan data melalu observasi, dokumentasi, dan wawancara secara mendalam. 
Adapun informan pada penelitian ini ialah Pendamping CSR PT. Pertamina Rewulu Mas Eky, Pendamping dari Joglo TaniMba Rully dan Mas Salim, Bapak Kepala Desa Bapak Joko Wahyu Triyono, Karang Taruna Mas Cahyo, Pengurus Kelompok Ternak Ngudi Mulyo Bapak Basri (Ketua Ternak), Anggota Ternak Ngudi Mulyo Bapak Ngadiran, Bapak Srikamto, Bapak Bukiyo dan lain-lain yang dianggap dapat menjawab rumusan masalah yang peneliti sedang kaji.

Informan diambil sesuai dengan kebutuhan data dan sasaran secara mendalam. Dari hasil data yang diperoleh dilapangan peneliti akan melakukan penyeleksian data dan pembuangan data yang tidak relevan. Setelah itu akan dilakukan pengkajian lebih mendalam dengan memahami data-data yang telah dihasilkan dalam penelitian tersebut agar mendapatkan kebenaran laporan lalu pengambilan kesimpulan.

\section{HASIL DAN PEMBAHASAN}

\section{Implementasi Program CSR PT. Pertamina (Persero) Fuel Terminal} Rewulu

Sebagai wujud tanggung jawab sosial kepada masyarakat, PT. Pertamina (Persero) Fuel Terminal Rewulu melalui CSR melakukan pengembangan potensi desa dan masyarakat di sekitar wilayah operasional. Salah satunya dengan memaksimalkan potensi Kelompok Ternak Ngudi Mulyo yang ada di Dusun Panggang. Di dusun tersebut program masih belum berjalan secara maksimal karena rata-rata warganya kurang memiliki kesadaran untuk mengelola kelompok ternak tersebut. Faktor yang paling berpengaruh adalah karena anggota kelompok ternak mayoritas lanjut usia, sehingga produktivitas menurun dibanding yang masih muda.

Dengan adanya permasalahan di atas, CSR PT. Pertamina (Persero) Terminal Rewulu melakukan evaluasi program untuk memilah lagi program-program yang bisa dijadikan evaluasi oleh Kelompok Ternak Ngudi Mulyo. Sebab masih banyak program yang perlu dibenahi jika melihat dari beberapa faktor. Berikut beberapa bentuk implementasi program yang sudah direalisasikan oleh CSR PT. Pertamina (Persero) Fuel Terminal Rewulu terhadap Kelompok Ternak Ngudi Muluo Panggang: 


\section{Pembuatan Kandang Komunal}

Dilansir dari Puslitbang Peternakan, bahwasanya kandang koloni/ komunal/ kelompok merupakan model kandang dalam suatu ruangan yang didalamnya ditempatkan beberapa ekor ternak, berfungsi sebagai tempat perkawinan dan pembesaran anak sampai disapih, atau digunakan sebagai kandang pembesaran maupun penggemukan? .

Kandang komunal artinya model kandang dalam suatu ruangan kandang ditempatkan beberapa ekor ternak, secara bebas tanpa diikat. Kelebihan sistem perkandangan ini adalah ternak lebih bebas dan adanya rak penyimpanan pakan kering (seperti jerami) sehingga pakan hijauan kering selalu tersedia ${ }^{8}$.

Program CSR PT. Pertamina (Persero) Fuel Terminal Rewulu yaitu memberi bantuan kepada Kelompok Ternak Ngudi Mulyo Panggang berupa kandang komunal. Dari pihak tersebut yang diwakili oleh M. Rizky Pratama memberikan bantuan berupa bahan material, seperti kayu, beton, dan yang lainnya kepada 10 anggota kelompok ternak di Dusun Panggang.

Dari CSR PT. Pertamina (Persero) Fuel Terminal Rewulu memberikan contoh kandang yang efektif untuk ternak sebab selama ini yang dibangun oleh anggota kelompok terbilang memakan banyak lahan serta bersifat individualis. Hal ini mengakibatkan program kelompok tersebut tidak berjalan dengan baik karena pemanfaatan kotoran serta kegiatan lainnya dilakukan bukan secara berkelompok.

Kandang komunal sendiri bertujuan agar anggota kelompok ternak Ngudi Mulyo Panggang dapat mengelola hewan ternak secara bersama, kemudian mampu untuk memanfaatkan kotoran ternak tersebut bersama pula, misalnya untuk kompos. Jadi, harapannya adalah pemanfaatan hasil ternak maupun ternak itu sendiri secara bersama-sama untuk mempererat hubungan dalam kelompok tersebut.

\footnotetext{
7 Hano Hanafi, “Peran Kandang Sistem Komunal Ternak Sapi Potong Terintegrasi Limbah Pertanian Dalam Mendukung Kedaulatan Pangan Di Yogyakarta Role of Communal Systems Stables of Cattle Livestock Integrated of Agricultural Waste in Support of Food Sovereignty in Yogyakart," Agros 18, no. 2 (2016): 126-33.

8 Ainur Rasyid and Hartati, Perkandangan Sapi Potong, 2007.
} 


\section{Pembentukan Badan Hukum (Legalitas)}

Dalam pembentukan badan hukum (legalitas), hal-hal yang perlu diperhatikan yaitu: 1) Prosedur pendirian. Pendirian badan usaha yang menggunakan badan hukum harus ada pengesahan dari pemerintah terhadap akta pendirian dan anggaran dasarnya. Sebagai gambaran pada akta pendirian suatu perseroan terbatas disahkan oleh Menteri Hukum dan HAM (Pasal 7 ayat (4) UU Perseroan Terbatas); 2) Pertanggung jawaban. Dalam badan usaha yang berbadan hukum, pertanggung jawaban pendiri/ pemegang saham terhadap perikatan badan usaha kepada pihak ketiga hanya sebatas modal yang dimasukan kedalam badan usaha. Sedangkan badan usaha yang tidak menggunakan badan hukum, pertanggungjawabannya akan sampai harta pribadi pendiri tersebut alias tidak ada pembatas; 3) Selanjutnya ketika sebuah kelompok yang sudah berbadan hukum kelompok tersebut mendapat pengakuan secara resmi oleh pemerintah dan mendapat perlindungan dalam menjalankan kegiatan oleh badan hukum. Tetapi jika ada penyalahgunaan dana dari kelompok tersebut, hal itu bisa di proses ke jalan hukum karena adanya perlindungan dari pemerintah ${ }^{9}$.

Legalitas untuk Kelompok Ternak Ngudi Mulyo sendiri didasari oleh kebutuhan kelompok agar keberadaan kelompok tersebut diakui secara hukum. Pembentukan badan hukum bagi kelompok ternak dilakukan oleh notaris yang ada di daerah Bantul. Yang pertama dilakukan yaitu meminta data-data dari kelompok ternak tersebut, seperti fotocopy KTP anggota, tandatangan, surat pengesahan dari kelurahan, dan lainnya. Setelah melakukan hal tersebut, kemudian diajukan ke notaris, lalu menunggu verifikasi sesuai dengan waktu yang diberikan oleh notaris terkait. Kemudian nama Kelompok Ternak Ngudi Mulyo berubah menjadi Kelompok Ternak Ngudi Mulyo Panggang.

\section{Posyandu Ternak Bekerjasama dengan Joglo Tani}

Setiap bulannya, CSR PT. Pertamina (Persero) Fuel Terminal Rewulu mengadakan posyandu ternak untuk melihat kondisi hewan ternak di

\footnotetext{
9 Yohana, "Tanggung Jawab Hukum Atas Bentuk Usaha Badan Hukum Dan Bentuk Usaha Non Badan Hukum," Jurnal Mercatoria 8, no. 1 (2015): 48-51.
} 
Kelompok Ternak Ngudi Mulyo Panggang. Dokter hewan memberikan vitamin serta obat cacing tergantung dari kondisi masing-masing hewan ternak. Selain itu, CSR PT. Pertamina (Persero) Fuel Terminal Rewulu juga bekerjasama dengan pihak Joglo Tani yaitu Salim dan Ruli.

Sebelum adanya posyandu ternak, Kelompok Ternak Ngudi Mulyo kurang memperhatikan kesehatan dan gizi hewan ternak mereka. Hal ini membuat banyak hewan yang rentan terkena penyakit sehingga dapat menghambat pertumbuhan hewan ternak. Oleh sebab itu, tujuan CSR Pertamina mendirikan posyandu ternak agar memberikan nutrisi yang cukup serta selalu mengecek kesehatan hewan ternak. Ketika hewan ternak merasa lebih sehat masa pertumbuhan mereka lebih cepat dan terhindar dari penyakit.

\section{Penanaman Tanaman Khusus Pakan Ternak (Kaliandra)}

Tanaman kaliandra berasal dari Meksiko, Amerika Tengah, masuk ke Indonesia pada tahun 1936 lewat pulau. Tanaman kaliandra masuk ke pulau Jawa berasal dari Guatemala selatan yaitu spesies Caliandra Calothyrsus berbunga merah dan Caliandra Tetragona berbunga putih. Daun kaliandra berwarna hijau gelap, kanopi melebar ke samping, dan sangat padat $^{10}$.

Kaliandra tumbuh pada daerah yang mempunyai curah hujan 700-5000 mm/th, biasanya dengan satu musim kering yang pendek antara 3-4 bulan, serta dengan sebaran tanah masam. Kaliandra sendiri memiliki bermacam-macam manfaat, antara lain; sebagai pakan ternak, bisa juga untuk kayu bakar, produksi madu, serta pelindung kopi ${ }^{11}$. Jadi penanaman kaliandra yang di lakukan oleh CSR PT. Pertamina (Persero) Fuel Terminal Rewulu selain untuk meningkatkan kualitas nutrisi kepada hewan ternak

\footnotetext{
10 Abqoriyah, Ristianto Utomo, and Bambang Suwignyo, "Produktivitas Tanaman Kaliandra (Calliandra Calothyrsus) Sebagai Hijauan Pakan Pada Umur Pemotongan Yang Berbeda Productivity of Calliandra (Calliandra Calothyrsus) as a Forage in The Different Defoliation Time" 39, no. 2 (2015): 103-8.

${ }^{11}$ Dwi Rahayu Ningtyas, “Uji Pertumbuhan Tanaman Jagung (Zea Mays L,.) Dan Kaliandra Merah (Calliandra Calothyrsus Meisn,.) Pada Tegakan Acacia Mangium Willd. Parung Panjang Bogor"' (UIN Syarif Hidayatullah, 2008).
} 
juga bisa membantu para peternak dengan menjadikan tanaman kaliandra sebagai kayu bakar misalnya.

Program penanaman pakan ternak berupa kaliandra dirasa tepat sebab kaliandra memiliki nutrisi yang bagus untuk memenuhi kebutuhan ternak. Program ini dilakukan mendekati musim penghujan tiba, sebab kaliandra cocok ditanam di area yang sering terjadi hujan.

Penanaman tanaman kaliandra memanfaatkan lahan kosong disekitar kandang milik anggota kelompok ternak. Kegiatan ini dilakukan oleh teman-teman Praktek Pengembangan Masyarakat (PPM) UIN Sunan Kalijaga Yogyakarta, Karang Taruna Rismada, Kelompok Ternak Ngudi Mulyo Panggang serta dari pihak CSR PT. Pertamina (Persero) Fuek Terminal Rewulu, mereka bahu-membahu menanam kaliandra yang berjumlah sekitar 100 bibit pada pertengahan bulan Desember 2019.

\section{Hasil Program CSR PT. Pertamina (Persero) Fuel Terminal Rewulu}

Pembuatan kandang komunal bagi Kelompok Ternak Ngudi Muylo dirasa sangat membantu sebab dengan adanya pemberian bahan-bahan material, sehingga mereka tidak perlu mengeluarkan uang yang begitu banyak. Selain itu, terjaga kebersihan lingkungannya dikarenakan tidak dibangun di belakang rumah warga. Serta dilaksanakan pula pengecekan rutin oleh dokter hewan maka akan terjamin kesehatan ternaknya.

Kemudian hasil dari adanya pembentukan badan hukum bagi Kelompok Ternak Ngudi Mulyo sendiri mereka merasa diakui oleh pemerintah, lalu jika ada beberapa hal yang dibutuhkan bisa meminta kepada pemerintah. Namun sebenarnya belum dirasakan hasil yang signifikan, mengingat program ini baru direalisasikan.

Lalu dengan adanya posyandu ternak sendiri sangat berguna bagi anggota Kelompok Ternak Ngudi Mulyo Panggang sebab bisa meminimalisir pengeluaran mereka semisal hewan ternaknya sedang sakit. Pengobatan maupun vitamin ditanggung oleh CSR PT Pertamina (Persero) Fuel Terminal Rewulu. Apalagi didampingi oleh ahlinya dalam bidang peternakan yaitu dari komunitas Joglo Tani, yang mana tidak hanya fokus di bidang pertanian saja namun juga termasuk peternakan. 
Selanjutnya hasil yang didapat dari penanaman tanaman khusus pakan ternak (kaliandra) sendiri adalah kelompok ternak tidak perlu mencari pakan kambing hingga ke sawah sehingga mereka dapat mengefektifkan waktu yang dimilikinya. Mereka juga mungkin menjadi bertambah ilmunya mengenai tanaman khusus pakan hewan ternak, atau barangkali juga bisa mengembangkan hal tersebut untuk berbisnis.

\section{Tanggapan Masyarakat Dusun Panggang Terhadap CSR PT. Pertamina (Persero) Fuel Terminal Rewulu}

Masyarakat Dusun Panggang, termasuk Kelompok Ternak Ngudi Mulyo merasakan berbagai hal dengan hadirnya CSR PT. Pertamina (Persero) Fuel Terminal Rewulu. Berdasarkan hasil wawancara peneliti dengan anggota kelompok ternak, diperoleh beberapa ringkasan. Salah satunya dari Bapak Paridjo, berikut tanggapannya mengenai CSR PT. Pertamina (Persero) Fuel Terminal Rewulu.

"Kalau saya puas sekali, merasa beruntung dari CSR Pertamina yang memerhatikan lingkungan. Saya mengucapkan terimakasih. Apalagi bantuannya sudah banyak sekali dan bagus sekali. Kalau boleh saya nilai hanya $60 \%$ tanggapan dari kelompok ternak untuk program CSR karena dilihat dari kerjasamanya. Kalau nanggapi senang semua tetapi tanggapan dalam pratiknya para petani juga belum maksimal seperti bantuan material yang sudah diberikan CSR sampai lebih 1 bulan masih belum dikerjakan material masih utuh.

Bapak Paridjo merasa terbantu dengan adanya CSR PT. Pertamina (Persero) Fuel Terminal Rewulu. Namun disisi lain beliau prihatin sebab para petani kurang memiliki rasa antusias dalam menyikapi hal tersebut. Bapak Hasan Basri, ketua Kelompok Ternak Ngudi Mulyo juga berkomentar.

"Dari CSR Pertamina mencarikan dokter hewan, setiap sebulan sekali. Dokternya kan ke kandang-kandang, setiap kita punya ternak yang sakit ya dokter itu yang menangani. Dari CSR itu. Ya saya rasa itu dari CSR itu sudah bagus, karena sudah tanggungjawab, membantu masyarakat lingkungan, tidak sini saja, ada yang di Plawonan, ada yang di sebelah Gamol. Setiap dusun beda-beda, kalau sini kandang, kalau yang lain mungkin pertanian. Mas ekky sering kesini. Kalau pertemuan dia kesini. Biasanya mas ekky datang, pendampingnya juga datang." 
Kemudian ada anggota lainnya, Bapak Srikamto, turut menambahkan.

"Ya setuju mba, sayangnya itu orang-orangnya, malah saya kasihan sama orang CSR sudah istilahnya orangnya sini berusaha untuk mengajukan sini tapi sini tidak bisa di ajak maju itu sulit, engga tau kendalanya apa itu karena anak anak sini kan umumnya ternak itu hanya untuk samben toh mba bukan untuk istilahnya bisnis. Malah aku malu juga dengan CSR itu saya kan dulu mengusulkan ini tempat kompos ini, saya itu tujuan saya semua kotoran itu kotoran hewan dijadikan satu disitu, jadi semua kandang itu kelihatan bersih untuk contoh kandang yang sehat itulah. Tapi kenyataannya engga bisa, engga bisanya ada kendalanya gini, ada yang bilang "Pak Pupuknya mau saya pakai sendiri" nah gitu terus ada yang pupuknya itu di kumpulkan disitu. Saya itu kepinginnya itu tiap minggu itu seperti ini kandang itu bersihkan kotorannya diatruh situ."

Rata-rata tanggapan anggota Kelompok Ternak Ngudi Mulyo Panggang, menyatakan program CSR PT. Pertamina (Persero) Fuel Terminal Rewulu sudah memberikan hal-hal yang dibutuhkan mereka, namun dalam realisasinya masyarakat kurang bisa menumbuhkan kesadaran. Artinya mereka masih sukar untuk diajak jika ada program apapun itu. Serta faktor usia anggota kelompok ternak tersebut membuat mereka sudah tidak begitu produktif lagi. Selain itu, kendala yang lainnya yaitu mereka hanya menjadikan berternak sebagai pekerjaan sampingan, sehingga dalam pelaksanaan kegiatannya kurang maksimal.

\section{Evaluasi Program CSR PT. Pertamina (Persero) Fuel Terminal Rewulu}

Pengertian evaluasi secara umum dapat diartikan sebagai proses sistematis untuk menentukan nilai sesuatu (ketentuan, kegiatan, keputusan, unjuk-kerja, proses, objek dan yang lainnya) berdasarkan kriteria tertentu melalui penilaian. Evaluasi yaitu menentukan nilai sesuatu dengan cara membandingkan dengan kriteria tertentu ${ }^{12}$.

Dalam hal ini, evaluasi dapat diartikan sebagai proses identifikasi untuk mengukur atau menilai apakah sebuah program dilaksanakan sesuai perencanaan dan berhasil mencapai tujuan atau tidak, kemudian dilakukan

\footnotetext{
12 Mahirah B, “Evaluasi Belajar Peserta Didik (Siswa)," Idaarah: Jurnal Manajemen Pendidikan 1, no. 2 (2017): 257-67, https://doi.org/10.24252/idaarah.v1i2.4269.
} 
perbandingan antara hasil akhir dengan rencana yang diinginkan. Dari situlah dicapai kesimpulan mengenai tujuan yang dijalankan.

Dari beberapa program yang sudah dijelaskan sebelumnya beserta hasil yang diperoleh, dapat dibahas mengenai evaluasi dari program CSR PT. Pertamina (Persero) Fuel Terminal Rewulu. Dari program yang pertama yaitu pembuatan kandang komunal sudah berhasil direalisasikan dan memberi hasil yang cukup baik bagi kelompok ternak di Dusun Panggang. Artinya kedepannya bisa diterapkan di kelompok ternak yang lain atau dimanapun sebab sangat berguna pembuatan kandang komunal tersebut.

Kemudian dari program yang kedua yaitu pembentukan badan hukum (legalitas). Mengenai program ini, tidak begitu bisa memberi hasil yang positif ataupun negatif sebab belum dirasakan efeknya. Sebab legalitas baru-baru ini diterapkan. Kedepannya mungkin perlu dilakukan monitoring kembali terhadap Kelompok Ternak Ngudi Mulyo Panggang setelah mendapat legalitas.

Selanjutnya program posyandu ternak. Disamping dampak positif yang sudah disebutkan sebelumnya, nyatanya ada beberapa anggota kelompok ternak Ngudi Mulyo yang kurang berantusias dengan adanya kegiatan tersebut. Meskipun begitu, sebenarnya hal ini sangat memberikan manfaat sebab selain adanya bantuan dari pihak CSR berupa dana, ada pula pendampingan dari Joglo Tani yang memang menguasai bidangnya. Selain itu, anggota kelompok ternak juga bisa bertanya dengan leluasa kepada dokter hewan yaitu Bapak Bowo, jikalau ada permasalahan terkait hewan ternaknya atau apapun yang berkaitan dengan ternak.

Untuk kedepannya, bisa diterapkan terus mengenai posyandu ternak sebab memiliki manfaat yang nyata bagi kelangsungan Kelompok Ternak Ngudi Mulyo Panggang. Terkait masyarakat yang kurang antusias, perlu diberi arahan kembali bahwa kegiatan tersebut sebenarnya sangat menjanjikan.

Program yang terakhir yaitu penanaman tanaman kaliandra. Memang benar, hasil nyata yang sudah disebutkan sebelumnya bahwa dengan adanya program tersebut dapat mengefektifkan waktu kelompok ternak sebab tidak perlu mencari pakan di sawah. Namun kenyataannya mereka masih ingin menggunakan tanaman dari yang mereka cari sebagai 
pakan ternak, padahal dilihat dari segi kandungan nutrisi tanaman kaliandra pun sangat bagus. Mungkin saja mereka lebih merasa 'nyaman' dengan mencari pakan sendiri, dibandingkan dengan melakukannya secara bersama.

\section{SIMPULAN}

Berdasarkan penelitian yang telah dilakukan CSR PT. Pertamina (Persero) Fuel Terminal Rewulu, peneliti menyimpulkan bahwa CSR PT. Pertamina (Persero) Fuel Terminal Rewulu telah melakukan implementasi program pemberdayaan masyarakat yang berada di ring 1 PT. Pertamina (Persero) Fuel Terminal Rewulu, dimana hal tersebut sebagai wujud rasa syukur dan terima kasihnya kepada masyarakat Dusun Panggang Argomulyo Sedayu. CSR PT. Pertamina (Persero) Fuel Terminal Rewulu telah berupaya melakukan pemberdayaan masyarakat kepada Kelompok Ternak Ngudi Mulyo Panggang. CSR PT. Pertamina (Persero) Fuel Terminal Rewulu mengajak masyarakat berpartisipasi dalam program yang telah diberikan oleh perusahaan tersebut, guna untuk menunjang kemitraan ekonomi dan kesejahteraan ekonomi Kelompok Ternak Ngudi Mulyo Panggang.

Program yang diberikan oleh PT. Pertamina (Persero) Fuel Terminal Rewulu berupa charity, cappacity building, infrastruktur dan empiwormen. Respon anggota Kelompok Ternak Ngudi Mulyo Panggang atas program-program yang diberikan oleh CSR PT. Pertamina (Persero) Fuel Terminal Rewulu seperti pembuatan kandang komunal, pembentukan badan hukum (legalitas), posyandu ternak (bekerjasama dengan Joglo Tani) serta penanaman khusus pakan ternak (kaliandra) penuh antusias dan sudah dijalankan semua oleh para anggota Kelompok Ternak Ngudi Mulyo Panggang walaupun program tersebut tidak berjalan seperti yang diharapkan akan tetapi itu semua bisa dijadikan bahan evaluasi bagi masyarakat dan CSR PT. Pertamina (Persero) Fuel Terminal Rewulu agar berjalan dengan baik sesuai dengan tujuan yang ingin dicapai bersama. Karena anggota Kelompok Ternak Ngudi Mulyo Panggang notabenenya yang lanjut usia, hal tersebut menjadi salah satu factor yang mempengaruhi 
kinerja dan produktivitas kegiatan sedikit terhambat karena kurangnya pendampingan langsung dari pihak CSR.

Saran penelitian untuk CSR PT. Pertamina (Persero) Fuel Terminal Rewulu, dapat melakukan evaluasi bersama dengan anggota Kelompok Ternak Ngudi Mulyo Panggang mengenai persoalan-persoalan apa saja yang masih kurang dalam program-program yang telah dilakukan hal tersebut. Tujuannya agar program-program dapat berjalan dengan baik dan kemandirian masyarakatnya dapat berdiri sendiri tanpa adanya ketergantungan terus. Selain itu agar program menjadi berkelanjutan dan manfaatnya akan selalu dirasakan terus menerus. Karena program CSR dapat membantu dalam pengentasan kemiskinan yang terjadi di masyarakat, dibutuhkan evaluasi dan kerjasama antara pemerintah, perusahaan dan masyarakat setempat yang berada di ring 1 .

\section{DAFTAR PUSTAKA}

Abqoriyah, Ristianto Utomo, and Bambang Suwignyo. "Produktivitas Tanaman Kaliandra (Calliandra Calothyrsus) Sebagai Hijauan Pakan Pada Umur Pemotongan Yang Berbeda Productivity of Calliandra (Calliandra Calothyrsus) as a Forage in The Different Defoliation Time" 39, no. 2 (2015): 103-8.

Agustina, Nike. “Peran Corporate Social Responsibility (CSR) PT. Pertamina

Hulu Energy WMO Dalam Pengembangan Masyarakat Di Kecamatan Gresik." Jurnal Akuntansi Unesa 1, no. 1 (2012).

Akim, Inggit. "Implementasi Prinsip Corporate Social Responsibility ( Csr ) Berdasarkan Undang-Undang" 1, no. 1 (2017): 111-32.

B, Mahirah. "Evaluasi Belajar Peserta Didik (Siswa)." Idaarah: Jurnal Manajemen Pendidikan 1, no. 2 (2017): 257-67. https://doi.org/10.24252/idaarah.v1i2.4269.

Dani Amran Hakim, Agus Hermanto dan Arif Fikri Universitas. “Kebijakan Yuridis Pemerintah Daerah Terhadap Tanggung Jawab Sosial Perusahaan (Corporate Social Responsibility)." Jurnal Mahkamah 53, no. 9 (2013): 1689-99.

Dr. Alfitri, M.Si. Community Development Teori Dan Aplikasi. Edited by Wagoen. Cetakan 1. Yogyakarta: PUSTAKA PELAJAR, 2011.

Edi Suharto, Ph.D. Membangun Masyarakat Memberdayakan Rakyat (Kajian Strategis Pembangunan Kesejahteraan Sosial Dan Pekerjaan Sosial. Edited by SH Aep Gunarsa. Cetakan Ke. Bandung: PT Refika Aditama, 2014. 
Hadi, A. Chairul. "Corporate Social Responsibility Dan Zakat Perusahaan Dalam Perspektif Hukum Ekonomi Islam." AHKAM: Jurnal Ilmu Syariah 16, no. 2 (2016): 229-40. https://doi.org/10.15408/ajis.v16i2.4453. Hanafi, Hano. "Peran Kandang Sistem Komunal Ternak Sapi Potong Terintegrasi Limbah Pertanian Dalam Mendukung Kedaulatan Pangan

Di Yogyakarta Role of Communal Systems Stables of Cattle Livestock Integrated of Agricultural Waste in Support of Food Sovereignty in Yogyakart." Agros 18, no. 2 (2016): 126-33.

Hatu, Rauf A. "Pemberdayaan Dan Pendampingan Sosial Dalam Masyarakat (Suatu Kajian Teortis)." Inovasi 7, no. 4 (2010): 240-54.

KBBI. “Implementasi." kbbi.we.id, 2020.

Miradj, Safri, and Sumarno Sumarno. "Pemberdayaan Masyarakat Miskin, Melalui Proses Pendidikan Nonformal, Upaya Meningkatkan Kesejahteraan Sosial Di Kabupaten Halmahera Barat." Jurnal Pendidikan Dan Pemberdayaan Masyarakat 1, no. 1 (2014): 101. https://doi.org/10.21831/jppm.v1i1.2360.

Ningtyas, Dwi Rahayu. “Uji Pertumbuhan Tanaman Jagung (Zea Mays L,.)

Dan Kaliandra Merah (Calliandra Calothyrsus Meisn,.) Pada Tegakan Acacia Mangium Willd. Parung Panjang Bogor." UIN Syarif Hidayatullah, 2008.

Nugraha, Joko Tri. "Pelaksanaan Peraturan Daerah Kabupaten Bekasi Nomor 6 Tahun 2015 Tentang Tanggung Jawab Sosial Dan Lingkungan Perusahaan (Studi Kasus PT. Pembangunan Deltamas)" 105, no. 3 (1945): 129-33.

Nugroho, D. "Implementasi Program Pemberdayaan Masyarakat Melalui Pelatihan Keterampilan Dasar (Studi Di Kecamatan Tambaksari Kota Surabaya)." Jurnal Administrasi Publik Mahasiswa Universitas Brawijaya 1, no. 5 (2013): 862-71.

Nursiyamsih, Eka. "Kehidupan Sosial Ekonomi Petani Dalam Sistem Sewa Adol Oyodan Masyarakat Pedesaan." Universitas Negeri Semarang, 2015.

Permana, Sasmito, Gunawan. "IMPLEMENTASI PROGRAM KELUARGA HARAPAN UNTUK MEMUTUS RANTAI KEMISKINAN DI KOTA MALANG ( Studi d i Kecamatan Lowokwaru Kota Malang ) Arif Citra Permana , Cahyo Sasmito , Cakti Indra Gunawan . Universitas Tribhuwana Tunggadewi Malang PENDAHULUAN Kemiskinan D." Jurnal Politik Dan Sosial Kemasyarakatan 10, no. 2 (2018): 64-74.

Rasyid, Ainur, and Hartati. Perkandangan Sapi Potong, 2007.

Retno, Sitaresmi Suryani, Yuli Rohmiyati, and Jazimatul Husna. 
"Pemberdayaan Masyarakat Melalui Perpustakaan: Studi Kasus Di Rumah Pintar 'Sasana Ngudi Kawruh' Kelurahan Bandarharjo-Semarang." Jurnal Ilmu Perpustakaan 4, no. 2 (2015): 15766.

Rezeki, Sri, and Fredian Tonny Nasdian. "Hubungan Keberhasilan Program Corporate Social Responsibility (CSR) PT Unilever Dengan Keberdayaan Perempuan Pedesaan." Jurnal Sains Komunikasi Dan Pengembangan Masyarakat [JSKPM] 4, no. 2 (2020): 261. https://doi.org/10.29244/jskpm.4.2.261-274.

Soetomo. PEMBERDAYAAN MASYARAKAT (Mungkinkah Muncul Antitesisnya?). Edited by Dimaswids. Cetakan II. Yogyakarta: PUSTAKA PELAJAR, 2015.

Suyitman, Lily Warly, Hellyward. "Pengelolaan Peternakan Sapi Potong Ramah Lingkungan." Jurnal Hilirisasi IPTEKS 2, no. 3 (2019): 159-76.

Teguh Aris Munandar; Dadan Darmawan. "Implementasi Program Pemberdayaan Masyrakat Miskin Pada Komunitas Nelayan Tradisional Untuk Kesejahteraan Sosial Ekonomi Di Lontar Kabupaten Serang." Jurnal Eksistensi Pendidikan Luar Sekolah 5, no. 2 (2020): 126-33. Yohana. "Tanggung Jawab Hukum Atas Bentuk Usaha Badan Hukum Dan Bentuk Usaha Non Badan Hukum." Jurnal Mercatoria 8, no. 1 (2015): 48-51.

Yuniarti Wahyuningrum, Irwan Noor, Abdul Wachid. “Pengaruh Program Corporate Social Responsibility Terhadap Peningkatan Pemberdayaan Masyarakat (Studi Pada Implementasi CSR PT. Amerta Indah Otsuka Desa Pacarkeling Kecamatan Kejayan Kabupaten Pasuruan)." Jurnal Administrasi Publik Mahasiswa Universitas Brawijaya 1, no. 5 (2014): 10915. 